\title{
Unequal Access to Maternal and Neonatal Health in Indonesia with Gender Perspective
}

\author{
Sartiah Yusran', Deborah Thomas ${ }^{2}$, Ulfa Matoka ${ }^{3}$, Eliyanti Agus Mokodompit ${ }^{4}$ \\ \{s.yusran@uho.ac.id ${ }^{1}$, deborah.graneggerthomas@gmail.com², ulffa.matoka@gmail.com ${ }^{3}$, \\ elimokodompit@yahoo.com ${ }^{4}$ \} \\ ${ }^{1,3,4}$ Faculty Public Health of Halu Oleo University, Kendari \\ South East of Sulawesi, Indonesia \\ ${ }^{2}$ Healthcom Consulting, 2266 Tinto Street, Victoria, BC V8S3A2. Canada
}

\begin{abstract}
The status of Maternal and Neonatal Health (MNH) is a marker of society's commitment to women and children. The Indonesia Demographic and Health Survey (IDHS) data indicates neonatal mortality has platitude and IDHS 2012 found an estimated Maternal Mortality Ratio of 359 per 100,000 live births. Millennium Development Goals (MDGs) was not met, then, the future efforts have been accommodated through Sustainable Development Goals (SDGs). The main objective of this study is to analyse a social development pattern of maternal and new-born health issues in Indonesia and to find out the evidence-based on barriers to access on MNH services. This qualitative study was conducted and focused on several districts in four provinces. Primary data was carried out through 125 in-depth interviews, Ten Focus Group Discussion, involving a total of 195 informants. Observation was conducted in Eight Community Health Centre and Five Integrated Service Station (posyandu) at the village level, and secondary data was collected from health related reports and journals. This study reveals that there are wide disparities in $\mathrm{MNH}$ outcomes and service coverage across the provinces of Indonesia and the worst outcomes tending towards the eastern islands of Papua and West Papua, Nusa Tenggara and Maluku. Within provinces and districts, inequalities in MNH outcomes according to wealth, well-being, mother's education, and location of residence exist. The evidence-based on barriers to access on MNH services are varies and the main barriers are including, home-based, communitybased, journey-based and service-based barriers. This reinforces the need for context specific programming at the district level, according to the geographical context and socio-economic conditions of the target group.
\end{abstract}

Keywords: Maternal and New-born Health, Neonatal Health, Social Development Analysis and Indonesia.

\section{Introduction}

The process of decentralization in Indonesia has created an array of institutional and governance issues which affects the functioning of the health system and the effectiveness of government agencies to work together to address underlying social determinants of health. The lack of clarity in functional assignment between levels of government has resulted in overlapping responsibilities and confusion and tension between them. Inter-sectors coordination on health is less than optimal particularly on family planning despite its role in reducing maternal mortality and promoting women's health. The capacity of provincial government to play a technical oversight and monitoring role has been weakened. Weak 
public financial management is a major concern across the country which affects the availability and quality of health services and the motivation of health staff, and inevitably hurts the poorest and least influential worst [1].

Government of Indonesia's National Development Plan (2016-2020) includes gender as one of three cross-cutting issues to be addressed across all development sectors. Gender mainstreaming is compulsory for all national institutions, and local governments are required to establish gender working groups, and to formulate policies, programs and activities from a gender perspective in the local government medium term development plan, strategic plan and work plan of local government work units. Beneath this overarching policy framework, gender mainstreaming in the health sector in practice appears formula. Misconceptions related to gender persist among health officials with gender often being equated with the delivery of services to women. Sector leadership on gender needs revitalizing.

Nationally, Gender and reproductive health have a moral foundation rooted in Indonesia's major religions, and patriarchy norms are deep seated in policies and programming. Women's sexuality and reproduction is circumscribed to the confines of marriage, and issues such as adolescent sexual and reproductive health, safe abortion, premarital sex and childbirth outside of marriage and are contentious and morally sensitive topics. As a result, gender gaps in the health system include the lack of routinely collected sex disaggregated data on utilization of health care and very little information on sex-disaggregated mortality, morbidity or health risk factors [2],[3].

At the same time, the decentralized governance system adds to the potential evaporation of national policies as district governments set their own priorities and approaches. In the area of safe delivery, some local governments have introduced regulations enforcing facility based deliveries and imposing fines on women that disobey. While this appears to have encouraged facility deliveries it also runs the risk of penalizing innocent women who were unable to reach a facility in time for the delivery. Regulating facility deliveries also runs the risk of creating a false evidence base of extremely high institutional deliveries as health providers avoid capturing home deliveries in records [3].

The Ministry of Health's Strategic Plan 2016-2019 refers to equity in terms of distribution and availability of health services and health resources, and has a value statement that states that 'attaining the highest possible health degree for every person is one of the human rights that does not differentiate between ethnic groups, religion and social economic status.' However, the strategy does not include an analysis of health status and coverage by wellbeing/poverty, the barriers to access of poor and vulnerable populations or strategies for improving the health of the poorest or those living in remote or vulnerable situations. Likewise, the Ministry of Health endorsed a National Action Plan on Maternal Health (20162030 ) in 2015. However, two main reasons indicated as challenge for this Program of Action due to the implementation challenges at sub national levels and this may hinder the achievement of national goals on maternal health. There continues to be a need to address equitable and universal access, particularly for young people to reproductive health services. This does not include an equity analysis of the groups or geographical areas where maternal mortality is higher and in need of an accelerated response. Commitment to address the underlying social determinants of health, including gender, appears to be missing in the policy frameworks that guide MNH [4].

Therefore, the main purpose of this study is to provide a social development analysis of maternal and new-born health issues and to close the socio-economic and geographical equity gap in maternal and neonatal deaths. The research question is "what are the main barriers that women face in accessing MNH services. 


\section{Methods}

A qualitative study was conducted and focused on eight districts in four provinces. This exploratory visit to two districts in East Java, one districts in West Nusa Tenggara Province (NTB), three districts East Nusa Tenggara Province (NTT), two districts in Papua. Primary data was collected through 125 in-depth interviews, ten Focus Group Discussion of 7 participants involving a total of 195 informants and observation was conducted in eight community health centre and 5 Posyandu (integrated service station) at the village level. Secondary data was collected from health related reports and journals. The guidelines for FGDs and in-depth interviews included the topics of maternal and neonatal health program, health provider's experience, community experiences with antenatal and postnatal care services, and reasons for not attending the services, and cultural practices during antenatal and postnatal periods and barriers to access maternal and neonatal services in community health centres and other post for MNH services. Participants of this study included district officials, district hospital management, health providers, community health centre representative, Posyandu cadres, family planning cadres, community leaders, health facility users, and community men and women in every province with stratify purposive random sampling.

\section{Results}

Gender issue has been identified as determinant factors in the effort to reduce maternal mortality rate and subsequently infant morbidity and mortality rate. In maternal and neonatal health (MNH) in particular, the issue of gender equality is considered as a crucial aspect that need to be addressed to ensure that pregnant women and their newborn received adequate access, timely and quality service for ante-natal, peri-natal and post-natal care.

A number of key barriers to accessing MNH services has been identified through this study starting from home-based, community-based, journey-based and services-based barriers. This considerable evidence of the barriers facing by women in accessing MNH services and the additional hurdles those poor and vulnerable women and their families have to contend with. These barriers are multiple and interconnected. Therefore, a pathway approach use to identify the constraints that women, and particularly those that are poor and vulnerable, have to contend with from home, in the community, related to the journey, and at the point of service delivery.

Diagram 1 below sets out the key barriers mentioned. This draws out key findings from the literature and from field visits in NTT, NTB, East Java, and Papua

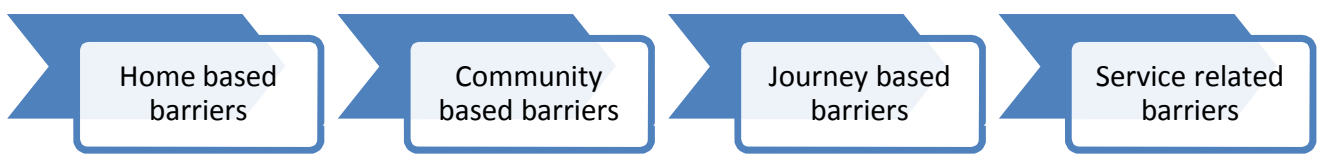

Diagram 1. Key barriers of MNH services.

The above diagram shows the dynamic of barriers contributing to the unmet need of MHN program. This framework identifies implicitly some thematic barriers such as gender, financial, traditional and cultural beliefs, and lack of information appear at several points along the demand to supply pathway. The Australia Indonesia Partnership for Maternal and Neonatal Health (AIPMNH) project reports mentions that its program has been focused on tackling service-based barrier. However, those linked to the journey with limited attention to 
home and community-based barriers are still less focus due to lack of understanding the root of the problems. In addition, Independent reviews of maternal health programs in Indonesia suggest this is an area in need of greater attention [5].

\section{(a) Gender}

\section{- Gender issues on the demand side}

Gendered social norms that affect decision making in the household are reinforced by community structures and practices. Gender norms tend to define domestic tasks and child care as women's responsibilities [6]. Division of labour within the family often leaves women with heavy and physically demanding work burdens through to the end of pregnancy, impacting on their health and the baby. This is often reinforced by local beliefs that hard work at the end of the pregnancy usually strengthens women for an easier delivery. Women often leave the facility early after delivery in order to get home to take care of older children putting their health and their newborn baby at risk. Gender norms also affect women's control over household resources and their access to cash at the time of an emergency [4]. This also mentioned in the 2012 IDHS that nationally, among women aged 15-49 who earn cash some $65 \%$ decide how that money is spent, and that $83 \%$ of women of the same age group report being involved in decisions about their health care. These are important indicators of women's empowerment, although the IDHS found that the strength of their association with health outcomes is weaker than expected.

Problems women face in accessing health services underlining some roots of both internal and external problems of a household [7]. The IDHS also asked women whether they faced specific problems in accessing health services for themselves when they are sick. This study has captured the range and magnitude of the problems across the research area. The magnitude of the difficulties women face is much higher in Papua and West Papua than the other three provinces, with the biggest challenge reported in both being getting money for treatment. This is closely followed in Papua by the distance to a health facility and reflects the physical remoteness and scarcity of services. While getting permission to go for treatment is not widely reported in East Java, NTB or NTT, it is $25 \%$ of women in West Papua and Papua consider getting permission as a problem. Such findings underscore the diversity of the demand side scenarios in each of the provinces, and the need for context specific approaches to demand generation.

In decision-making perspective, understanding how family control over resources and decision-making patterns are played out in local socio-cultural environments and affect access to health care is important for programming [8]. It was commonly reported that women need to seek family permission to leave the village, and lack of involvement in decision-making about their health. In Papua, decision-making process is complicated as both husband's and wife's families have to be involved in deciding whether to seek care outside of the village, and once at a facility whether to accept the treatment being offered. This can be a major delaying factor at the time of an emergency. Staff at district and referral hospitals in Papua reported that this was often the cause of delayed action, with for example parents-in-law in a remote village in the Highlands needing to be consulted in deciding whether a woman has a caesarean section at a distant hospital.

Furthermore, in women's social solidarity point of view, social structures in some areas, such as on the island of Sumba (NTT) leave women without the space to come together and receive new information, dialogue with peers, and build solidarity and self-confidence. In contrast in the Highlands of Papua, women's groups linked to the church tend to meet 
regularly. The existence and capacity of women's groups and networks which can act as a platform for empowering women varies across the focal provinces. Even where women's groups are functional, women are generally not involved in community level discussions and decisions. Village Musrenbang (community discussion for development planning) tend to be male dominated and hardware oriented. This translates into women typically not being aware of their entitlements, or having a say in the allocation of community resources in a way that will address women's collective poverty. This can be argued that lack of women's voice in village level can be a signal of less empowerment of women's group.

\section{- Gender issues on the supply side}

It is linked to a range of issues which affect women's access to services. Facilities seem poorly staffed and facilities may be poorly located so as to be accessible to women, and inadequately designed to cater to women's basic needs such as functioning and accessible clean toilets, and screens for maintaining privacy. Service sites tend not to be sensitive to the needs of disabled women. Practitioners have lack the skills and knowledge to respond to their special maternal needs [9]. Lack of respect and compassion fosters women's confidence and trust, especially for particularly vulnerable women such as unmarried pregnant women, and those living with HIV.

\section{(b) Financial}

In the home and community, they were lack of awareness of health entitlements, including Jamkesmas (Health insurance scheme for the poor) and Jampersal (Childbirth Insurance). Lack of confidence of providers will not demand additional expenses results in considerable uncertainty in the household as to the affordability of services, particularly so for the poor and near-poor [10]. IDHS 2007 found that women reported "getting money for treatment" the biggest problem they face in accessing health care. In 2012 this was surpassed at the national level by "not wanting to go alone"; though in Papua, West Papua and NTB access to money remained the biggest problem.

Financial difficulty in another emerged as the major issue among women who did not fulfil the minimum requirements of four antenatal care services or two postnatal care services within the first month after delivery [10],[11]. This was related to the cost of health services, transportation costs, or both. In remote areas, especially if the village midwife frequently travelled out of the village, the distances from health facilities, in addition to poor road conditions were major concerns, particularly for those living in remote areas.

It was also found that less than half of the poorest, $30 \%$ of the population have received Jamkesmas. Ineffective targeting of this health insurance scheme for the poor leaves many poor and vulnerable people unprotected. At the same time, many wealthier households receive benefits they are not entitled to and the World Bank found that this health insurance coverage of the bottom $30 \%$ of the population ranges from between $39-50 \%$ while coverage of the top $60 \%$ ranges from $36 \%$ to $7 \%$ [12]. Decentralized targeting of health insurance scheme for the poor has reportedly added to targeting errors. World Bank reports that research have found Jamkesmas card holders experiencing longer-than-normal delays in facilities because service providers needed to verify their health insurance's status or it took long way to provide a referral. This was also reported in all four provincial field studies. Discrimination in favor of regular paying patients has also been reported as well as charges for covered medicines and services. [12]. 
In Papua, several health insurance schemes for the poor are provided, both from local government and from national level. They are theoretically available at public health institutions. The reimbursable for delivery patients is more attractive from local health insurance but this is only offered to indigenous Papuans. As a final source of health insurance, some hospitals will administer childbirth insurance, but as the reimbursable is the lowest. This childbirth insurance also requires a referral letter from a community health centre and where these are non-functional such as in the remote Highlands, this is difficult to avail.

It is argued that the administrative burden for hospitals of administering three or more health insurance schemes, and the confusion and lack of awareness among the public of what each offers should be simplified with the introduction of universal health coverage but exactly who ends up benefitting and social exclusion will need close monitoring by the health system and civil society.

In the context of transportation, cost of transport is not covered by any of the health protection schemes. It is often the most expensive cost that families have to cover, especially in remote areas [10]. The use of fund for health operational assistance to cover the referral transport costs from a lower to a higher level facility is available in some places. However, as the study team learned in Papua, these referral funds are typically neither publicized nor openly offered to those being referred. Their ability to protect vulnerable women and children in need of referral services are therefore modest in their current form.

\section{(c) Tradition, Cultural Beliefs and Customs}

Traditionally, cultural beliefs and customs affect family decision-making and gender norms as discussed earlier, maternal and child health practices, and are important determinants of maternal and early child health and under nutrition [13]. They vary across ethnic, tribal and social groups and need to be understood as part of the socio-cultural domain of specific groups rather than generalised. For example, the strong importance of cultural festivities in parts of NTT, and preference for large families have significant implications on household poverty, maternal and newborn health, and behaviour change campaigns need to be shaped accordingly.

For more precise meaning of these traditional and cultural beliefs and customs, for example, restrictions during pregnancy are common. In Papua and NTT, we learned of food prohibitions during pregnancy. For example with eggs prohibited in NTT, and rice, tofu, and lentils are not allowed in Papua. Taboos related to pregnancy were also documented. Women in NTB, East Java and Papua reported how they kept their pregnancy secret until their bellies visibly showed. This tradition with obvious implications for delayed antenatal care. At the same time, trust in traditional birth attendants was reported in all the field sites visited. The District Health Office has decided to train traditional birth attendants as a first line of care to pregnant and delivering women. It can be argued that strengthening relationships of Traditional Birth Attendances (TBAs) with the formal health system and building their capacities will need to be considered in according with the different health system and social contexts in which the program will operate.

Positive and being beliefs are a source to leverage for improving positive $\mathrm{MNH}$ behaviours and use of services. Harmful beliefs and practices, such as women and newborns put into "smoking huts" for 40 days post-delivery in NTT to cleanse the blood, and damaging dietary restrictions during pregnancy work against MNH. There is a need respectful multidimensional social mobilisation approaches to help reframe the behaviours they support. In another situation, across provinces, mothers-in-law are influential family figures. The field visits reported in several sites, they deterred breast feeding, and Indonesia's poor record with 
early and exclusive breastfeeding generally. In fact that women who have delivered in a health facility are more likely not to breastfeed. This issue illustrates the need for improved training of health providers and regulation to prevent companies selling infant formula from accessing facilities.

Furthermore, social shame or 'shame culture' hides away social issues and contributes to vulnerability and exclusion of those who have broken social codes, such as unmarried pregnant women. [14] Stigma and shame attached to pregnancy outside of marriage feeds into the isolation of young, unmarried pregnant women and their lower take up of pregnancy care and institutional delivery, and increased risk of maternal mortality. In West Lombok, one community health centre reported undertaking "silent home visits" to unmarried pregnant women to provide antenatal care and encourage them to come for an institutional delivery. These practices illustrate the need for special provider attention to very vulnerable women.

Lack of access to reproductive health information for unmarried men and women places young people at risk of unwanted pregnancies, abortion and early marriage and childbearing [4],[15]. In NTB, NGOs supporting adolescent reproductive health information programs are campaigning for "new men" that share household and child care tasks and are involved in maternal and child health. It can be concluded that young people are also identified as vulnerable group and become a challenge for their healthy life style. This indicates a need for collaborative work between NGO and government in promoting reproductive health information for adolescent. Opportunities to link with other demand side programs, such as international program, particularly in the areas of reproductive health will be essential to leverage local resources and stimulate action [15].

\section{(d) Authoritative attitudes}

Husbands and mothers-in-law, village leaders, and health providers are vested the authority to take decisions which impact on maternal and newborn health. This affects the level and form of interpersonal communication between the provider and user, and often leaves women uninformed of basic information on how they can promote their health, what they are entitled to, and why facility deliveries are beneficial [16].

Local regulations that impose fines on women that don't deliver in a facility while wellintentioned can end up penalising the most vulnerable that were unable to reach a facility in time. Similarly, the translation of national health financing policy so that health insurance scheme for the poor and childbirth insurance beneficiaries of institutional delivery funding are pressured into accepting IUDs, is another example of how authoritative attitudes can undermine choice and transparency [17],[18].

\section{(e) Remoteness and Geography}

The issue of remote or isolated area and geography are major barriers to accessing services in some of the focal districts. Particularly Papua and West Papua, where road and water access are often absent, and villages can only be reached by foot or sometimes plane. Remoteness impacts on access to: 1) information; 2) the distance to; 3) costs in reaching services including time; 4) the availability of transport; 5) the availability of health personnel and medical supplies; and 6) the cost of running health services. In addition, the low level of human development in poor remote areas also impacts the capacity to mobilise and train community facilitators and local people [19].

Based on the above pictures, tailored interventions to address the special challenges remote communities face in accessing services are often needed. Interview result identified 
that waiting homes are being experimented with, and 'Desa Siaga' or the 'alert village' program is mobilizing and organizing the community to be prepared with community based transport solutions, social funds, and support networks. The 'Alert Village' program applies with communities assuming the responsibility for awareness of the risks of pregnancy and childbirth, and supporting registered pregnant mothers with funding and transportation for emergency obstetric assistance, and identified blood donors. Harmonizing program interventions to maximize the use of limited local human resources and create linkages across development efforts also makes sense [5]. However, this national program is very depending on the commitment of the local government and coordinating team is a challenge due to the involvement of several sectors and other resources.

Drawing on the national and international evidence-based, it will be essential that the new program addresses key information gaps through empowering and participatory BCC (Behaviour Change Communication) approaches as well as traditional campaign approaches. Provider knowledge and interpersonal communication skills also need to be strengthened for them to fulfil their role as key informers and influencers. As the new program expands to include family planning, informed choice will be a central issue and will reinforce the need to give greater attention to information dissemination and behaviour change communication.

\section{(g) Poor availability and quality of care.}

Another major barrier to access in MHN service is related to poor availability and quality of care issues [8]. Weaknesses in district health systems play out at the community health centre level in terms of poor staff attendance, lack of operational funds, accountability deficits, and less than respectful and client-oriented care. In some districts, staff distribution is uneven leaving remote areas without staff and functioning primary level services. In Paniai, Papua, the district headquarters town has more midwives stationed in the hospital and community health centre than the rest of the entire district. This is in part because staff use personal connections to avoid remote postings, and also because non-indigenous health workers lack the language skills and backgrounds to operate in remote areas. Security threats also persist and young women are particularly vulnerable. Related to weak human resource management is the sometimes inappropriate sitting of health facilities driven by political influence or availability of donated land rather than population coverage and access.

A qualitative study of community member's perspective conducted in West Java province in Indonesia has found main barriers including the limited availability of health services, the distances from health facilities, especially poor road conditions were also major concerns, particularly for those living in remote areas. Similar study conducted in the region found that one of the main barriers in maternal and neonatal health services in Indonesia was quality of care [9],[20].

It is sad to say that community participation and ownership are almost absent. In general, service delivery at post of integrated services remains weak with untrained cadres due to lack of allocation funding provided. This condition has closed related to the local government commitment on maternal and neonatal health issues [21].

The absence of a community-based health and nutrition provider that is trained to provide information, counselling, treatment of common ailments and referral leaves a gap in the health system especially in poor and underserved areas and districts, and particularly in remote areas. The weaknesses of Post of integrated services are well spelled out in Lucy Mize's "The paradox of Posyandu" [22]. Evidence suggests that Post of integrated services are not a vehicle as currently structured and capacitated to fill the basic $\mathrm{MNH}$ information and service gap at community level in high burden areas. Other village actors with the potential to affect 
MNH practices, such as Family Empowerment and Welfare Movement and Family Planning Cadre are not felt to be functioning well. The PSF study found local women organization in village to be largely not functioning. This study found Family Planning Cadre has little supervision, receive limited training, and are not well coordinated with other actors. Religious and community leaders are generally not engaged in the area of $\mathrm{MNH}$ [7]. Interestingly, national program for community empowerment has trained community health and nutrition facilitators as part of its stunting initiative. For sustainability and institutional clarity it would seem better for such a facilitator to be linked to the health system rather than a community empowerment project. Therefore, an innovative project design will be well positioned to test out approaches to filling the information deficit, empowering women to use new information, and strengthening frontline delivery of $\mathrm{MNH}$ and related nutrition and family planning services at community level in order to reduce barriers for assessing MNH services with culturally acceptable approach.

\section{Conclusion}

This study concludes some constrains and a number of evidence describing barriers that women face in accessing MHN services including: home-based, community-based, journeybased and services-based barriers. The factors that hindered utilization of antenatal and postnatal care services in this study include gender issue in demand and supply sides, financial difficulties, tradition, cultural beliefs and customs, authoritative attitude, physical distance to health facilities (remoteness and geography), a limited availability of information and misunderstanding about the health insurance prevented poor communities from fully benefitting from the insurance scheme. These barriers are multiple and interconnected and a pathway approach reinforces the need for context specific programming at the district level, according to the geographic context and socio-economic conditions of the target group, particularly those that are poor and vulnerable.

\section{Reference}

[1] Titaley, C.R., Dibley, Michael JRoberts, Christine L, Factors associated with nonutilisation of postnatal care services in Indonesia. Journal of Epidemiology \& Community Health, 63 (10): p. 4, 2009.

[2] Thomas, D. and A. Raintung, Social Development Assessment of PERMATA:, 2013.

[3] Yusran, S. and A. Raintung, Social Development Assessment of PERMATA, 2013.

[4] O'Donnell, O., Access to health care in developing countries: breaking down demand side barriers. Cadernos de saude publica, 23: p. 2820-2834, 2007.

[5] R. Davies, K. Makowiecka, and Siti Nurul Qomariyah, Review of four maternal health programs in Indonesia between 2006 and 2010 (IMHEI, IMHI, SISKES, WCHPP). A synthesis of the findings of the Independent Monitoring and Evaluation Team (IMET).", 2010.

[6] Paruzzolo, S., et al., Targeting poverty and gender inequality to improve maternal health, 2010.

[7] Bhutta, Z.A., et al., Countdown to 2015 decade report (2000-10): taking stock of maternal, newborn, and child survival. The lancet, 375 (9730): p. 2032-2044, 2010.

[8] Jacobs, B., et al., Addressing access barriers to health services: an analytical framework for selecting appropriate interventions in low-income Asian countries. Health policy and planning, 27 (4): p. 288-300, 2011.

[9] Titaley, C.R., M.J. Dibley, and C.L. Roberts, Factors associated with underutilization of 
antenatal care services in Indonesia: results of Indonesia Demographic and Health Survey 2002/2003 and 2007. BMC public health, 10 (1): p. 485, 2010.

[10] Ensor, T. and J. Ronoh, Effective financing of maternal health services: a review of the literature. Health policy, 75 (1): p. 49-58, 2005.

[11] Khan, A.A., Zahidie, Aysha., Rabbani, Fauziah, Interventions to reduce neonatal mortality from neonatal tetanus in low and middle income countries-a systematic review. BMC Public Health, 13 (1): p. 322, 2013.

[12] Bank, W., 2012.

[13] Kraft, J.M., et al., An evidence review of gender-integrated interventions in reproductive and maternal-child health. Journal of health communication, 19 (sup1): p. 122-141, 2014.

[14] Collins, E.F. and E. Bahar, TO KNOW SHAME: Malu and Its Uses in Malay Societies. Crossroads: An Interdisciplinary Journal of Southeast Asian Studies, 14 (1): p. 35-69, 2000.

[15] Titaley, C.R., Hunter, Cynthia L Heywood, Peter., Dibley, Michael J, Why don't some women attend antenatal and postnatal care services?: a qualitative study of community members' perspectives in Garut, Sukabumi and Ciamis districts of West Java Province, Indonesia. BMC pregnancy and childbirth, 10 (1): p. 61, 2010.

[16] Mpembeni, R.N., et al., Use pattern of maternal health services and determinants of skilled care during delivery in Southern Tanzania: implications for achievement of MDG-5 targets. BMC pregnancy and childbirth, 7 (1): p. 29, 2007.

[17] Yusran, S., Perempuan dan Kesehatan. Jurnal Kuncup Pertiwi TP-PKK Provinsi Sulawesi Tenggara, Volume 4 (2) 2006, Pages 31-34, 2006.

[18] Yusran, S., School-based Sexual and Reproductive health education is timely. Proceeding of 20th Jurnal Perempuan, Indonesia, 2016, pp 1997-2013, 2016.

[19] Sari, Y.I., Rahman, and Manaf, Evaluation of PNPM RESPEK: Village infrastructure and institutional capacity", 2011.

[20] Brooks, M.I., et al., Health facility and skilled birth deliveries among poor women with Jamkesmas health insurance in Indonesia: a mixed-methods study. BMC health services research, 17 (1): p. 105, 2017.

[21] Prost, A., et al., Women's groups practising participatory learning and action to improve maternal and newborn health in low-resource settings: a systematic review and metaanalysis. The Lancet, 381 (9879): p. 1736-1746, 2013.

[22] Crigler, L., Henry Perry, Rose Zulliger, Kerry Scott, Dena Javadi, Jessica Gergen, Katharine Shelley, Lauren Crigler, Iain Aitken, Said Habib Arwal, Novia Afdhila, Yekoyesew Worku, Jon Rohde, and Zayna Chowdhury, 2012. 